Article

\title{
Exploring Lobbying Practices in Israel's Nonprofit Advocacy Organizations: An Application of the Libby Lobbying Model
}

\author{
Patricia Libby ${ }^{1, *}$, Laura Deitrick ${ }^{2}$ and Rita Mano ${ }^{3}$ \\ 1 Pat Libby Consulting, San Diego, CA 92116, USA; patlibby@patlibby.com \\ 2 Department of Leadership Studies, University of San Diego, San Diego, CA 92110, USA; \\ lauradeitrick@sandiego.edu \\ 3 Department of Human Services, University of Haifa, Mount Carmel, Haifa 31905, Israel; \\ ritamano@research.haifa.ac.il \\ * Correspondence: patlibby@patlibby.com
}

Received: 1 September 2017; Accepted: 16 October 2017; Published: 24 October 2017

\begin{abstract}
Nonprofit and voluntary associations around the world are the primary vehicle for representing the voices of citizens in the policy-making process. As scholars who are committed to advancing the role of civil society and the citizen, it is incumbent upon us to provide theoretical and practical frameworks that can assist nonprofits with this important work. In developed nations, the similarity between societal values and structures in democratic countries makes it possible to assess and advance best practices for policy advocacy regardless of the origin of those advocacy models. This research introduces a recently developed conceptual framework originally deployed to diagnose nonprofit organizations in the U.S. engaged in legislative advocacy. Applied to 12 Israeli nonprofit organizations involved in legislative advocacy and seeking to advance change through the legislative process, this paper assesses and expands the proposed model confirming that most facets of the U.S. framework were commonly used by Israeli nonprofits. There is also evidence that culturally embedded norms are the main source for deviations from the model applied in the U.S.
\end{abstract}

Keywords: nonprofit; nongovernmental; lobbying; civil society; advocacy; social change

\section{Introduction}

Welfare states in developed nations around the world are in a state of flux due to lingering post-recession economic uncertainties and population changes resulting from shifting demographics and immigration. As legislators in these nations wrestle with the economic and social implications of nationalism versus globalism, they find themselves face to face with fundamental questions about the role of government and the rights of the individual to social support.

As service providers (frequently on behalf of or in collaboration with the state) and as representatives of low-income and other politically under-represented groups, nonprofits are uniquely positioned to enter these debates (Berry 2005; Donaldson 2007; Kimberlin 2010; Hasenfeld and Garrow 2012). Yet often, for a variety reasons, they do not. For example, many nonprofit leaders are unclear about the laws and processes pertaining to political activity by nonprofits (Deitrick et al. 2014). As a result, they tend to err on the side of caution and limit, in many cases unnecessarily, their political activities. When they do engage, it is in very low-levels of activity (Schmid et al. 2008; Salamon 2008). As scholars who are committed to advancing the role of civil society, the citizen, and for many, the non-citizen, it is incumbent upon us to provide theoretical and practical frameworks that can assist nonprofits with this important work.

When nonprofits engage in advocacy, their efforts can take many forms, ranging from direct lobbying (Berry and Arons 2003; Donaldson 2007; Kimberlin 2010; Hoefer 2015; Libby 2012), to 
increasing civic participation, to providing opportunities for disempowered constituents to be heard by decision-makers (Boris and Mosher-Williams 1998; Unsicker 2012), to public education, to research on community needs, to monitoring policy implementation (Reid 2000, 2006; Libby 2012). When nonprofits choose to engage in direct lobbying (also known as legislative advocacy campaigns), scholars have proposed a variety of frameworks to guide them in these efforts (Berry and Arons 2003; Hoefer 2015; Libby 2012; Unsicker 2012).

The study presented here is the result of research focused on an analysis of the practices of Israeli nonprofits engaged in legislative advocacy using one such model (Libby 2012) that was initially intended to test the extent to which U.S. nonprofits engaged in legislative advocacy. In this study, the researchers sought to evaluate the fit of the U.S. model, while describing the activities of Israeli nonprofits.

It was assumed that the comprehensiveness of the Libby Lobbying Model would be sufficiently aligned to fit the practices of Israeli nonprofits deployed to engage in legislative advocacy activities. The Libby Lobbying Model presented here was developed organically over a period of eight years through observation of its practice within a statewide nonprofit advocacy organization based in Massachusetts, U.S. The most critical elements of the model were identified through trial/error and a systemic analysis of legislative practices of nonprofit advocacy organizations. Ten identifiable "steps" were finally organized and included in the proposed model that was thereafter used as a diagnostic and pedagogical tool for the evaluation of the performance of legislative lobbying campaigns in the U.S. The model has yielded mostly positive results in both Massachusetts and subsequently in California, where it was used to shape several successful advocacy initiatives. On the basis of the ten step model, further exploration was sought in a different setting to test how the practices apply in another democratic context. Israel was chosen as an empirically interesting setting to understand whether there was any discernable difference between the practices of U.S. and Israeli nonprofit advocacy organizations.

\section{A Brief Description of the Two States}

The state of California lies along the west coast of the United States. With 158,706 sq. miles, California is the third largest state by area in the country with Alaska and Texas being respectively larger. The population of the state is greater than 39 million (City-Data.com n.d.). There are 123,321 public charities in California (classified by the I.R.S. designation under section 501(c) (3) (Deitrick et al. 2014)). By comparison, Israel is a much smaller state consisting of 10,840 square miles (including the territories under Palestinian self-governance), that is situated along the southeast coast of the Mediterranean Sea. It is bordered by Lebanon in the north, Syria in the northeast, Jordan in the east, Egypt to the southwest and the Mediterranean Sea in the west (NSW Board of Jewish Education n.d.). Israel has a population of 6.5 million people and there are approximately 45,000 nonprofit organizations registered with the Israeli government (Israel Non Profit News n.d.). The nonprofit activity in Israel resembles that of the U.S.

Although the two states both function as democracies, their legislative systems are distinct. California operates under a separation of powers system with a two chamber legislature, and single member districts where the legislators are directly elected. The Israeli system is a parliamentary system with a single chamber and proportional representation where citizens vote for parties rather than individual candidates. The chamber is known as the Knesset. Relevant to this study, the laws governing the extent to which nonprofits may engage in political activity differ between the two states as well. In the United States, federal law limits political activity while there are no such limitations in Israel (Council on Foundations 2017).

While it is evident that this two state comparison is not perfectly aligned relative to the respective population or geographic size of these areas, the researchers deemed the comparison appropriate for purposes of this study, determining it to be more comparable than comparing a tiny nation to one of the largest democracies in the world. 


\subsection{Theoretical Background}

Organizations are social entities that exist and operate in a social, economic, cultural, political, technological and geographic context called the organizational environment. Understanding the organizational environment is essential to understanding the characteristics and structures of organizations and the processes that transpire within them. Organizations must adjust their products, structure, and human composition, as well as the way in which they operate in their environment. This is to say, the organization must adopt those characteristics that will enable it to survive in its environment. For example, a complex and diverse environment mandates that organizations operating within it develop flexible organizational systems that can quickly and easily be changed, which ensure "openness" to technological innovation, mobility of human resources for meeting changing tasks and so forth.

Understanding organizations as "open" systems that exist and operate through an abiding interdependence between their environment and themselves was the central turning point in studying the organizational phenomenon. According to this approach, the organization and its environment are mutually dependent. This dependence determines a significant part of the behavioral patterns of both the organization and the environment. Organizations have a perpetual need to acquire the resources essential for their continued existence in their environment and must ceaselessly pursue the supply of support that is necessary for their continued operations. Assessing the power of all of these factors (internal and external) that maintain the reciprocal relations between the environment and the organization and which are linked to its operations and outcomes must be correctly identified and assessed (Mano 2010, 2014).

Ben-Ner and Van Hoomissen (1991) used the economic theory of the sorting of stakeholders to claim that voluntary organizations are controlled first of all by "demand-side stakeholders" that are interested in supplying certain services to themselves as consumers and/or for the benefit of others. Among these are high-demand stakeholders such as donors and supporting institutions that ensure and promote preferred third sector organizations to realize their goals on the condition of "market failure", when products and services are not supplied properly either regarding quantity or quality (Abzug and Webb 1999). As a result they can supply needed material to the organization.

According to Clarkson (1995), advocacy organizations tend to maintain relations with certain groups of stakeholders as opposed to other groups and in this way differentiate between the primary stakeholders - without whom the organizations cannot survive for very long — and those who influence or are influenced by the organization but do not have a reciprocal relationship with it and are not vital to its continued existence, for instance, the media or other such influential groups. In a study undertaken in the area of services in Israel, stakeholders were categorized according to two criteria: their positions vis-à-vis the organization and the degree to which they are important to the organization.

Advocacy organizations provide representation and consulting in many areas-health, education, civil rights, etc. Lobbying processes seek the sources of power in society (Shapley and Shubik 1954; Banzhaf 1965; Young 2004) in order to instigate change by affecting the decision-making process assuming that given opinions concerning the particular resolution are at stake. In order to promote the interests of the groups they represent they need to periodically or constantly engage in direct lobbying (aka legislative advocacy campaigns). Seeking to empower the interested groups and underlying causes, lobbying is one among other strategies to effectively pursue support from the public and its political representatives (Boris and Mosher-Williams 1998; Unsicker 2012). The power game outcomes are often the process of (a) tapping into the strongest source of influences (b) estimating the appropriate strategies to attain the desire outcomes and (c) choosing to pursue the most "satisficing" rather than "optimized" goals.

Scholars have proposed a variety of frameworks to guide them in these efforts (Berry and Arons 2003; Hoefer 2015; Libby 2012; Unsicker 2012). Advocacy organizations make these efforts choosing different forms of influence from direct lobbying (Berry and Arons 2003; Donaldson 2007; Kimberlin 2010; Hoefer 2015; Libby 2012), to increasing civic participation, to 
providing opportunities for disempowered constituents to be heard by decision-makers (Boris and Mosher-Williams 1998; Unsicker 2012), to public education, to research on community needs, to monitoring policy implementation (Reid 2000, 2006; Libby 2012).

\subsection{The U.S. Implementation of the Libby Lobbying Model}

Starting in 2003, the Libby Lobbying Model has been used to conduct legislative campaigns that resulted in enhanced protections for victims of domestic violence; a law permitting the expenditure of State of California funds in Mexico to prevent environmental pollution along the U.S.-Mexico border, age identification requirements for purchasing over-the-counter medications that could be abused in large quantities, mandated child-pornography reporter status for computer repair technicians, increased penalties and mandated liability insurance to stem client abuse by elder care facilities, and background check requirements for adults supervising unregulated youth sports leagues among other issues. When the passage of these laws was secured it was principally by nonprofit practitioners who did not have prior knowledge of the legislative process, since most of the lobbying process was conducted by graduate students who were guided by the model and advised by faculty. The majority of these students were employed in managerial positions within nonprofit organizations; however, often these legislative campaigns were not related to their profession but were of personal interest. Therefore, although the model has not been formally studied, it has been repeatedly used as a pedagogical tool that has frequently yielded legislative change when deployed as it was intended.

The model, presented in Table 1, was designed as a reflective practice of what happened naturally within the context of a U.S. advocacy organization. That dynamic begged the question: does the model travel well? How does it fit, or not, within a different cultural albeit democratic context?

Table 1. Libby Lobbying Model components.

\begin{tabular}{|c|c|c|}
\hline & Name of step & Types of Associated Activities \\
\hline 1 & Identify the issue & $\begin{array}{l}\text { - Assess staff perception of clients/community affected by issue } \\
\text { - } \\
\text { - } \text { assess those possibly affected through individual meetings, surveys } \\
\text { - } \\
\text { - } \\
\text { - } \\
\text { Responfer with other nonprofits with a similar mission } \\
\end{array}$ \\
\hline 2 & Research the issue & $\begin{array}{l}\text { - } \quad \text { Conduct surveys of those affected } \\
\text { - Gather data to document the issue } \\
\text { - } \quad \text { Consult experts } \\
\text { - } \text { Research similar laws that have been implemented }\end{array}$ \\
\hline 3 & Create a fact sheet Brand the issue & $\begin{array}{l}\text { - Create a name for the campaign that represents and encapsulates } \\
\text { the issue } \\
\text { Produce a fact sheet that includes key information on the issue, } \\
\text { a proposed solution, language to neutralize opposition } \\
\text { arguments, endorsers } \\
\text { - Present a financial analysis of the impact } \\
\text { - Present a story of someone affected }\end{array}$ \\
\hline 4 & & $\begin{array}{l}\text { - Produce a research paper that fully documents the issue and provides } \\
\text { - } \quad \text { legislative solution } \\
\text { - } \quad \text { Produce a petition } \\
\text { - } \quad \text { Document the issue with photographs } \\
\text { - Provide media coverage of the issue }\end{array}$ \\
\hline
\end{tabular}


Table 1. Cont.

\begin{tabular}{|c|c|c|}
\hline & Name of step & Types of Associated Activities \\
\hline 6 & $\begin{array}{l}\text { Map out supporters and detractors } \\
\text { Form a coalition }\end{array}$ & $\begin{array}{l}\text { - Create a list of other nonprofits that might join the campaign and } \\
\text { approach those parties for support } \\
\text { - Create a list of other organizations (for profit, nonprofit and public) } \\
\text { that might join the campaign and approach those parties for support } \\
\text { - Create a list of community leaders that might endorse the campaign } \\
\text { and approach those parties for support } \\
\text { - Consider who might oppose the issue, why, and how. Determine what } \\
\text { language and strategies could be used to address their concerns } \\
\text { and/or neutralize their arguments } \\
\text { - Create a list of legislators to be approached on the issue } \\
\text { Conduct research on the legislators to be approached to learn their } \\
\text { views on similar issues. For opponents, what strategies can be used to } \\
\text { address their concerns? }\end{array}$ \\
\hline 7 & Develop educational materials & $\begin{array}{l}\text { - Create a website about the issue or designated Facebook page } \\
\text { - Create training materials to educate members, friends, coalition } \\
\text { members about the campaign } \\
\text { - Provide sample letters, email templates, telephone dialogue that allies } \\
\text { can use to contact legislators }\end{array}$ \\
\hline 8 & Launch a media campaign & $\begin{array}{l}\text { - Contact reporters from various media outlets—print, } \\
\text { electronic, television }\end{array}$ \\
\hline 9 & Approach elected officials & $\begin{array}{l}\text { - } \quad \text { Meet with legislators } \\
\text { - } \text { research paper } \\
\text { - } \quad \text { Gring people affected by the issue } \\
\text { memberate letters and /or telephone calls to the elected officials from } \\
\text { memary organization and coalition organizations }\end{array}$ \\
\hline 10 & Monitor progress on the issue & $\begin{array}{l}\text { - Keep in touch with the legislator's office to track progress of } \\
\text { legislation, negotiate changes to legislation if needed, troubleshoot } \\
\text { problems with other legislators } \\
\text { - } \quad \text { Testify at hearings } \\
\text { - } \quad \text { Coet, as needed, with regulatory agencies } \\
\text { - } \quad \text { Continue to generate press } \\
\end{array}$ \\
\hline
\end{tabular}

\subsection{Assessing the Libby Lobbying Model in Israel's Advocacy Organizations: Methods}

Unlike the manner in which the model was introduced to nonprofit professionals in the U.S., in this instance the organizations studied did not have knowledge of the model prior to being interviewed. Organizations were chosen following a convenience sample method based on the geographic proximity of the research team, considering that few advocacy groups were determined to operate in Northern Israel. Accordingly, most of the organizations chosen for this study were considered small; managers were in charge of 2-4 organizational staff members, mostly volunteers. The data collection stage was held between in December 2013 to May 2014.

The study included data collected from nonprofit organizations whose principal aim is to promote civil rights, environment and national identity groups in Israel. Interviews of those organizations were conducted in Hebrew by graduate students at the University of Haifa following a guided interview protocol developed by the U.S. research team and under the guidance of the faculty at Haifa University. The guide contained both closed and open-ended questions. The majority of the questions utilized a five point Likert style scale (where $1=$ Not at All and $5=$ A Great Deal), allowing participants to rate the extent to which they engaged in specific lobbying practices identified in the Libby Lobbying Model. 
The interviews were completed within a period of four months. Once the interviews were complete, the graduate students created a transcript of each interview. A total of 12 interviews were transcribed from Hebrew into English and those interviews comprised the data set used for the analysis contained in this paper. Each interview represented an individual nonprofit organization that was currently or had been previously engaged in a lobbying campaign. No two organizations interviewed worked on the same campaign or the same type of issue.

A convenience sample composed of advocacy organizations in Northern Israel was collected. The organizations surveyed $(\mathrm{N}=12)$ included a highly diverse set of advocacy groups including health, civil rights, ethnic protest, environment protection, youth, women and education. While the sample is small it is fairly representative of the advocacy groups normally included in the list of the Central Bureau of Statistics (2012).

\section{Findings and Discussion}

The Libby Lobbying Model consists of ten distinct components which serve as the steps in the application and evaluation of successfully concluding the lobbying process. In this section an analysis of the findings are presented according to the components included in the model.

Step 1: Identify the issue. The transcripts translated into English indicate the student researchers identified twelve separate advocacy issues among the organizations. The range of advocacy issues presented was divergent and included, for example, proposed laws regarding overhauling voting procedures in the Knesset (the Israeli Parliament), a disabilities rights law, burial rights for non-Jewish soldiers, increased compensation for military service, a law concerning public housing, child health and safety laws, and environmental laws. One third of the organizations discussed a legislative campaign that had resulted in successful passage of a new law.

In their efforts to identify the issue, the most prominent strategy used "a great deal" by all but one responder, was obtaining information from the staff of the organization. The second most highly rated response was "talking to people in the community who we think are affected by a particular issue." Trailing only slightly was responding to an issue that had appeared in the news. The lowest response recorded was from those organizations that conducted focus groups. The second lowest response was from organizations that conducted constituent surveys.

Open-ended comments further indicated that most of the organizations engaged an issue identification process that involved direct involvement with individuals affected by an issue or professionals who serve those individuals as well as data obtained through a research process. To further illustrate these activities, Table 2 presents select responses from respondents who provided additional information about issue identification.

Table 2. Select Additional Responses to Identifying an Issue.

\footnotetext{
"We established a connection and talked with people who have different disabilities and with their relatives.

And following the applications we got from people with disabilities, we tried to understand and focus on the main problems they were coping with within the context of accessibility to higher education."

"The identification of the problem comes, generally, from current treatment problems, both in an open clinic framework and in the framework of service which we provide for treating private problems."

"I read many articles on this issue and talked with many professionals, both from the nonprofit sector and outside it, as well as people in government ministries. I put together a round table which included organizations serving deaf people, professionals and senior officials in Ministries of Education and Health were included. In the round table framework, we tried to clarify the need for additional analyses."

"I investigated the number of soldiers that were arrested due to a financial problem caused by the soldiers' wage erosion (which has not been updated for more than a decade) and the implications of their arrest to their future."

"[We conducted a] factual analysis concerning the number of existing programs regarding the coastal environment, what is planned for them and how they will influence the accessibility of the coast to a wider public."
} 
A few organizations were more heavily focused on a direct-action community engagement strategy to identify the issue they would promote. For example, one respondent said, "We initiated community activity against Amidar and we initiated meetings in the housing and other Knesset committees such as the Absorption of Immigrants, Welfare, Economics and such." Similarly, a different respondent said, "Demonstrations, distribution of flyers, participating in panels on this issue, presenting the question to the regional council.".

The type of laws the organizations were advancing or had attempted to advance was strikingly similar to the type of laws that nonprofits in the U.S. California context typically work to advance. In their efforts to identify the legislative issue the Israeli organizations sought to promote, the vast majority of respondents (all but one) reported relying on information from the staff. Although at first glance this could be misconstrued to an interpretation that these organizations were less apt to seek community input for the issue they sought to advance, the narrative portions of the survey revealed that organizations relied extensively on external data to identify the issue they sought to change.

As was previously mentioned, the lowest responses recorded were from those organizations that conducted focus groups and constituent surveys. This is clearly not a matter of cultural differences as several responders reported conducting surveys and focus groups. This could indicate that as a whole, staff sought out individuals to confirm their views rather than engage in larger scale community data-gathering strategies. Since the organizations studied were small in size with limited staff resources, it could also indicate that they did not have the means to engage in a more thorough community engagement process for identifying the issue they sought to promote.

Step 2: Research the issue. All of the organizations surveyed reported drawing upon data and experts to better understand their issue and to assemble information that would be used to promote it. All organizations reported "consulting experts on the issue" to a "great deal." Descriptions of their research activities included direct consultation with subject matter experts, collecting statistics and gathering anecdotal stories. One respondent said, "The activists are not so interested in documenting [the issue], they only want to act, and therefore there was almost no documentation [prior to our involvement]."

Other respondents conducted literature reviews and commissioned studies. For example, one respondent said, "We requested a paper from The Research and Information Center committee of the Knesset in order to validate our position in a neutral paper written by a professional and trusted entity." Another reported fighting to "get the official government data that was presented in the war against poverty (Alaluf Committee)." A different respondent described using Google and conducting analysis of aero-pictures and patrols in the areas related to their particular issue.

While all of the respondent organizations dedicated a "great deal" to "consulting experts on the issue," it was evident that some organizations debated the balance between information gathering and activism. For example, one respondent said, "The organization is a protest movement, which intends to turn the Galilee finger territory into an autonomous democracy. All of the activity is derived from this intention."

What cannot be discerned from the respondents is the extent to which their research helped them to determine the solution they proposed to address the issue (although it is evident in the steps that follow, that organizations did indeed propose solutions). Along a similar vein, without access to the documentation the advocates used to promote their issue, it cannot be determined whether or not more thoroughly documented and presented advocacy campaigns achieved greater success than those that were less well-documented and presented. Evidence from the U.S. lobbying campaigns using the Libby Model indicates that this is often the case, i.e., that the more well-researched the case, the more likely it is to find a sponsor and eventually to become a law.

Steps 3 and 4: Create a fact sheet/brand the issue. The most common strategies reported to be used "a great deal" by the vast majority of the organizations were producing a short fact sheet that included a proposed solution to the issue, producing a formal position paper that represented the results of the research that had been conducted, and presenting the story of someone who was affected by the 
issue. From the comments received it appeared that producing a formal position paper was at least a normative expectation of the legislative advocacy process (and possibly a formal requirement for advancing an issue within the Knesset).

Participants were least likely to produce a petition, however several organizations referenced "promoting through Facebook," or promoting the campaign through the website maintained by their organization which can also serve as a vehicle for gathering and documenting issue supporters. A few spoke about generating letters to legislators. The activity that received the second lowest ranking was conducting a cost-benefit analysis of the proposed legislation.

Participants also reported being aware of an array of strategies that could be used to advance their cause. When presented with a list that included items such as "publishing a list of individuals and organizations that had signed onto our campaign, drafting sample legislative language, producing a petition, using photographs to document the program" and other items contained in the description of steps three and four (referenced in Table 1), several provided comments similar to this one: "We did almost everything that was mentioned. What we did not do was not as relevant to this struggle."

It appeared to be a normative expectation or perhaps a procedural requirement for Israeli nonprofits engaged in lobbying to create a fact sheet and research paper. Surprisingly there was no apparent expectation that an organization would conduct a cost-benefit analysis of the issue it was seeking to promote. This was an interesting finding as it is extremely unusual for a U.S.-based organization to conduct a legislative campaign without presenting such an analysis, as legislators in that country tend to be less receptive to lobbying campaigns that do not have a fiscal analysis included.

Steps 5 and 6: Map out supporters and detractors/form a coalition. Most of the respondents reported making a list of the legislators they needed to approach to pass the law and doing this "a great deal." The lowest-ranking activities were conducting research on the members of the Knesset to learn how they voted on similar issues in the past and making a list of other types of organizations (other than allied nonprofits) that might join the campaign. A few respondents articulated strategies such as, "Part of the work of promoting a process like this is to meet the opponents, to hear the opposition and to try to decide what can be 'win-win' for everybody." Several respondents referenced tracking votes and doing an analysis of the press coverage of the issue.

The two lowest-priority activities reported in this section had to do with identifying supporters outside of the nonprofit community that might support the campaign and conducting research on members of the Knesset to learn how they voted on similar issues in the past. Although identifying "external" supporters is an element of this section of the ten-step Libby Lobbying Model, it was also not intuitive to U.S. practitioners when they were exposed to this idea. Organizations frequently believe they can carry out a campaign on their own and at times wrestle with other organizations about who should receive "credit" in the event they succeed in creating a new law. Therefore, it is not surprising that nonprofits advocating in another type of democracy would be hesitant to broaden their advocacy tent.

Two Israeli organizations spoke explicitly about meeting with individuals and organizations they believed would be opposed to the issue in an effort to understand the opposition perspective. This approach however, was much less nuanced than the more thoughtful strategic mapping process which is prescribed in the model.

What is less clear is why the Israeli organizations felt no need to investigate the individuals they would be lobbying. Perhaps this is because of the relatively small size of the country where individuals serving in the legislature may be more commonly known and therefore their views may be much more transparent. It may also be because the party system makes the views of the legislators more apparent. Even if this knowledge of legislators is apparent and transparent, a more strategic approach would be to understand the dynamics at play within the Knesset regarding supporters and opponents. For instance, nonprofits could identify the coalitions required to support a legislative proposal. Overall the level of mapping supporters and detractors that is suggested in the Model, i.e., the extent to which it is emphasized as a strategic tool, was not in evidence. 
Step 7: Develop educational materials. As a whole, the responses to this step were the lowest overall of any of the other steps queried, which is to say they fell either mid-way or closest to the "not at all" response on the 1-5 scale. Although several groups spoke about using Facebook to promote their issue, a more common response had to do with organizations promoting the issue through the media and publicizing the effort through partner organizations. A few made comments similar to this: "We do not provide phone numbers for communication. Only e-mails and/or fax; mainly e-mails. Telephone is not suitable at all."

Since the purpose of educational materials as advanced in the model, is to provide a vehicle to engage other citizens who are not so closely aligned with the issue with the tools to engage and advocate for it, it is closely linked to the lack of coalition building reported by the interviewees. In other words, if an organization does not seek out coalition members in order to broaden the activist network, there is no need for these types of educational materials.

An explanation for this lack of outreach to potential partner organizations might be found in the response of one interviewee who said, "Lobbying—creating a coalition, it is something that requires research in itself. Creating a coalition requires many resources aiming at creating a coalition and sometimes we run out of resources by creating the coalition and they do not stay to promote the campaign. This is an important and useful tool, but we cannot use it at any price because it is very expensive in terms of resources and not always relevant." Again, it should be noted that the organizations interviewed all had limited staff resources.

Step 8: Launch a media campaign. As mentioned in the findings on Step 7, promoting the issue through the media was a popular strategy. A typical response was as follows: "We had TV reports in Channel 2, Channel 10, TV debates, radio and others." Additionally, as was also previously noted, there was relatively little emphasis on activating stakeholder networks to support individual advocacy campaigns. In addition, several organizations considered making calls to legislators inappropriate. The strategies used by nearly all of the organizations focused on raising consciousness about the issue through social media, traditional media, and more generally, promoting the issue to the general public rather than targeting natural allies and supporters such as the members of stakeholder organizations. This is markedly different than strategies used by most U.S. organizations that seek to activate membership networks to promote their legislative issues. Instead, the following responses reflected the actions reported by many survey respondents. One said, "[we] created public opinion via mass-media channels." A different respondent said, "We had a televised report at the same time that a cabinet meeting related to the issue took place. We harnessed the media to support the legislation."

Steps 9 and 10: Approaching elected officials/monitoring progress on the issue. All respondents ranked highly the act of meeting with their elected officials and bringing prepared materials to the meeting; most also brought people affected by the issue to these meetings. In the open-ended section, many organizations made comments similar to this one: "We have a direct communication with the parliamentary assistants, who update us and also we update the Members of Knesset themselves" indicating an on-going relationship with those elected officials they were seeking to influence.

The responses to the questions posed in sections nine and ten of the survey neatly matched activities that are carried out by U.S. nonprofits when they engage in lobbying. Those responses included meeting with legislators, bringing materials to the meeting, and following up regularly with legislators and their aides.

Differences in reported elements in lobbying activities Although the survey participants reported using fact sheets and position papers "a great deal," as part of their efforts to promote their issue, several also reported civil disobedience activities pertaining to their campaigns. One respondent described their activities by saying, "We filed a petition with the Supreme Court, we ran an internet campaign, we did a protest demonstration, we promoted a struggle within the military and with the Knesset, and we wrote articles and conducted confrontation in the media." A second noted, "All of the activities we have done are without financing and intended mainly to wake the local public up to protest activities for freedom." In addition, several of those interviewed spoke about "a mass-media 
analysis" or similarly, "tracking the press" and said "we monitored opinion articles related to the issue to map the entities that supported these articles." While generating press is an element contained in the Model, monitoring and mapping the press is not explicit in it.

Another respondent identified the need for a charismatic leader as an essential component of an advocacy campaign, remarking as follows: "The leadership of the campaign is critical. There was no such component in the questionnaire and it is very important. There are three important things in the campaign: Media; Social relationships and leadership. Because you can see that two years ago there was a protest and it did not have a clear, charismatic, sweeping leader ... I have seen many examples of campaigns that have failed because of the lack of charismatic leadership."

\section{Limitations to the Study}

The research team acknowledges that the exploratory nature of the study coupled with its qualitative design limits the extent to which the findings may be generalizable to a larger population. The convenience sampling method and the small number of cases representing a single perspective within the organization provide at best an initial glimpse into the lobbying practices of nonprofits in Israel. The student researchers who completed the interviews were not fully trained in the subject of nonprofit lobbying or in the Libby Lobbying Model, which was used as the assessment model in the study. Thus, while the students were able to follow the interview guide provided, they lacked the ability and subject matter expertise required to formulate and ask appropriate follow-up questions.

After reviewing the data, the authors concluded that pre-determined probes would have been helpful to draw out nuanced information needed to more fully explain some of the common responses provided. For example, why was it the case that organizations did not do background research on the legislators they were approaching? Was it because they knew or believed they understood the views of those legislators or was it for another reason? Also, it cannot be assumed that because a specific topic or lobbying practice was not mentioned that it does not occur in practice, as the issue may not have been raised by the student researcher or it may not have come to mind for the respondent during the interview.

The study was also constrained by geographic boundaries and cultural and linguistic differences between the United States and Israel. For example, the interviews were conducted in Hebrew and then translated to English. Additionally, as outlined in the methods section of this paper, several of the authors were unable to meet directly with the student researchers. Thus, data from the study were drawn from literal translations of the interview transcripts. Simply put, some information could have been lost in translation or the culturally specific meaning of responses could have been misinterpreted by the authors.

Despite these limitations, the authors believe that the findings provide evidence, albeit initial, to address the research question posed in this paper: whether there was any discernable relationship between what is practiced in Israel among nonprofit advocacy organizations and what this model recommends. We believe that the evidence indicates the model is applicable.

In addition, there are several possibilities for continuing this line of research. The model could be taught prescriptively to Israeli nonprofits and a follow-up study done to see whether those elements that were less frequently deployed by the organizations surveyed here, such as mapping supporters and detractors and coalition-building, would be utilized to a greater extent and yield positive results. Alternatively or in addition, a study could be conducted with U.S. nonprofits that are engaged in advocacy that have not heretofore been exposed to the model. That type of research would yield a more "apples to apples" comparison of the lobbying practices of nonprofits in these two countries-particularly if the U.S. study group was comprised of smaller organizations.

\section{Conclusions}

Applying the Libby Lobbying Model as a comprehensive model made it clear that all ten elements contained within the model were applicable to the advocacy activities of nonprofit organizations in 
Israel. Organizations reported using elements of the model to greater or lesser degrees, but by and large embraced all aspects of it (although the "mapping" activities were scant). Those elements that were less frequently deployed may have been so because organizations lacked adequate resources to do so, or were not fully acquainted with the rationale for deploying a particular strategy. Since the U.S. organizations being used for comparison purposes here had received training on the model, those organizations implementing it had knowledge about the rationale for each component. Nonetheless, it was also obvious that several strategies deployed by the Israeli nonprofits were not contained in the model.

First and possibly most notably was the use of civil disobedience activities which is apparently less common among the nonprofit organizations observed in the U.S. that are attempting to pass legislation. This is likely because in the U.S. there is a common perception of a divide between "inside" players, i.e., those that work within the legislative system, and outside organizations, i.e., those that agitate, wherein different nonprofits take one role or the other. In the information provided through these interviews it appeared that several Israeli organizations assumed both roles. This supports existing and recent publications suggesting how in recent times the combination between advocacy and service provision makes it difficult to fully engage in autonomous strategies (Schmid et al. 2008; Mano 2014).

Second, it was also clear that many of the organizations studied conducted "a mass-media analysis" to track public perception of an issue and appeared to rely, as a whole, much more on public opinion as a vehicle for influencing legislators than on direct the mobilization of individuals to contact legislators about a specific issue. The use of the media this way is not contained in the model. That may be because it might be more difficult for nonprofits in the U.S. to gain on-going media coverage for their advocacy issues.

Finally, although it is always limiting to rely on the views of a single interviewee, it was interesting to read one respondent's views about the necessity of a charismatic leader. This idea is quite contrary to the model itself as the model was created as a vehicle that any citizen could use-in partnership with others-to assemble and guide a successful legislative campaign. The Israeli state has been historically affected and advanced by leaders who emerged in military settings and then served as prominent political figures.

We can conclude then that the Libby Lobbying Model is an adequate diagnostic tool to explore the lobbying activity in Israel as it is in the U.S. Possibly though, as is often the case, legal restrictions, or a lack thereof, as well as cultural differences in the political environment and general norms and values may affect tactics and considerations involved in the lobbying process. It is important to state that it is a rare case whereby a diagnostic model may be applied in exactly the same ways even within otherwise similar settings, possibly because the "civicus" aspects of public life are always more dynamic than our well-developed models.

Author Contributions: Pat Libby developed the model used in the study, analyzed the data and developed the findings. Laura Deitrick, co-conceived of the idea for the study, assisted with data analysis and developing the findings. Rita Mano, co-conceived of the idea for the study, identified the participant organizations, provided a contextual framework for the work.

Conflicts of Interest: The authors declare no conflict of interest.

\section{References}

Abzug, Rikki, and Natalie J. Webb. 1999. Relationships between Nonprofit and for-Profit Organizations: A Stakeholder Perspective. Nonprofit and Voluntary Sector Quarterly 28: 416-31.

Banzhaf, John F. 1965. Weighted voting doesn't work: A mathematical analysis. Rutgers Law Review 19: 317-43.

Ben-Ner, Avner, and Theresa Van Hoomissen. 1991. Nonprofit Organizations in the Mixed Economy. Annals of Public and Cooperative Economics 4: 519-50. [CrossRef]

Berry, Jeffrey M. 2005. Nonprofits and civic engagement. Public Administration Review 65: 567-78. [CrossRef]

Berry, Jeffrey M., and David F. Arons. 2003. A Voice for Nonprofits. Arlington: Oakland Street Publishing. 
Boris, Elizabeth, and Rachel Mosher-Williams. 1998. Nonprofit advocacy organizations: Assessing the definitions, classifications, and data. Nonprofit and Voluntary Sector Quarterly 27: 488-506. [CrossRef]

Central Bureau of Statistics. 2012. Isreal in Figures: Jerusalem 2012. Available online: http:/ /www.cbs.gov.il/ publications/isr_in_n12e.pdf (accessed on 10 October 2017).

City-Data.com. n.d. California—Location, Size, and Extent. Available online: http:/ /www.city-data.com/states / California-Location-size-and-extent.html (accessed on 31 August 2017).

Clarkson, Max E. 1995. A Stakeholder framework for analyzing and evaluating corporate social performance. Academy of Management Journal 20: 92-117.

Council on Foundations. 2017. Israel. Available online: https://www.cof.org/content/israel\#Political (accessed on 10 October 2017).

Deitrick, Laura, Jon Durnford, Jan Masaoka, and Kristen Woelslegel. 2014. Causes Count. San Francisco: California Association of Nonprofits.

Donaldson, Linda Plitt. 2007. Advocacy by nonprofit human service agencies: Organizational factors as correlates to advocacy behavior. Journal of Community Practice 15: 139-58. [CrossRef]

Hasenfeld, Yeheskel, and Eve Garrow. 2012. Nonprofit human service organizations, social rights, and advocacy in a neoliberal welfare state. Social Service Review 82: 1-28. [CrossRef]

Hoefer, Richard. 2015. Advocacy Practice for Social Justice, 3rd ed. Chicago: Lyceum Books.

Israel Non Profit News. n.d. Guide to Non Profits. Available online: http:/ /israelnonprofitnews.com/guide-tonon-profits (accessed on 24 September 2014).

Kimberlin, Sara E. 2010. Advocacy by nonprofits: Roles and practices of core advocacy organizations and direct service agencies. Journal of Policy Practice 9: 164-82. [CrossRef]

Libby, Pat. 2012. The Lobbying Strategy Handbook: 10 Steps to Advancing Any Cause Effectively. Thousand Oaks: SAGE Publications.

Mano, Rita S. 2010. Organizational crisis, adaptation, and innovation in Israel's nonprofit organizations: A learning approach. Administration in Social Work 34: 344-50. [CrossRef]

Mano, Rita S. 2014. Networking modes and organizational performance in Israel's nonprofit organizations. Nonprofit Management and Leadership 24: 429-44. [CrossRef]

NSW Board of Jewish Education. n.d. Geography of Israel. Available online: http://bje.org.au/course/israel/ geography/ (accessed on 10 October 2014).

Reid, Elizabeth J. 2000. Structuring the Inquiry into Advocacy. Washington: Urban Institute.

Reid, Elizabeth J. 2006. Nonprofit advocacy and political participation. In Nonprofits and Government: Collaboration and Conflict. Edited by Elizabeth T. Boris and C. Eugene Steuerle. Washington: Urban Institute Press, pp. 343-71.

Salamon, Lester. 2008. Nonprofit America: A Force for Democracy? Baltimore: Johns Hopkins University Center for Civil Society Studies.

Schmid, Hillel, Michal Bar, and Ronit Nirel. 2008. Advocacy activities in nonprofit human service organizations: Implications for policy. Nonprofit and Voluntary Sector Quarterly 37: 581-603. [CrossRef]

Shapley, Lloyd S., and Martin S. Shubik. 1954. A Method for Evaluating the Distribution of Power in a Committee System. American Political Science Review 48: 787-92. [CrossRef]

Unsicker, Jeff. 2012. Confronting Power: The Practice of Policy Advocacy. West Hartford: Kumarian Press.

Young, Dennis R., ed. 2004. Effective Economic Decision-Making by Nonprofit Organization. New York: The Foundation Center.

(C) 2017 by the authors. Licensee MDPI, Basel, Switzerland. This article is an open access article distributed under the terms and conditions of the Creative Commons Attribution (CC BY) license (http:/ / creativecommons.org/licenses/by/4.0/). 